\title{
Влияние концентрации водорода на фототок диодов Шоттки $\mathrm{Pd} / n-\ln P$
}

\author{
(C) Е.А. Гребенщикова ${ }^{1}$, В.Г. Сидоров ${ }^{2}$, В.А. Шутаев ${ }^{1}$, Ю.П. Яковлев ${ }^{1}$ \\ ${ }^{1}$ Физико-технический институт им. А.Ф. Иоффе Российской академии наук, \\ 194021 Санкт-Петербург, Россия \\ 2 ООО АИБИ, \\ 194021 Санкт-Петербург, Россия \\ E-mail: eagr.iropt7@mail.ioffe.ru
}

(Получена 1 августа 2018 г. Принята к печати 13 августа 2018 г.)

Исследована скорость изменения фототока короткого замыкания диодов Шоттки $\mathrm{Pd} / n$-InP в зависимости от присутствия водорода в газовой смеси с концентрацией $\mathrm{H}_{2}$ в интервале 1-100 объемных \%. Показано, что при одновременном воздействии на диод Шоттки газовой смеси, содержащей водород, и освещения $(\lambda=0.9$ мкм) концентрация водорода в газовой смеси и скорость изменения фототока диода $\mathrm{Pd} / n-\mathrm{InP}$ связаны между собой экспоненциально. С увеличением интенсивности освещения увеличивается скорость реакции диодов Шоттки на присутствие водорода в газовой смеси.

DOI: 10.21883/FTP.2019.02.47107.8967

\section{1. Введение}

Настоящая работа продолжает цикл исследований, направленных на создание фотоэлектрического датчика водорода на основе структур с палладиевым контактом к полупроводникам типа $\mathrm{A}^{\mathrm{III}} \mathrm{B}^{\mathrm{V}}$ для определения концентрации водорода в окружающей среде при различных температурах, включая комнатную [1-4].

В работе [5] сообщалось об исследовании фотоэдс МДП-структур $\mathrm{Pd} /$ оксид $/ n$-InP в зависимости от концентрации водорода в газовой смеси с целью разработки метода количественного определения содержания водорода в окружающей среде.

В данной работе представлены результаты исследования фотоэлектрических свойств структур с палладиевым контактом, не содержащих оксида индия и фосфора, a именно диодов Шоттки $\mathrm{Pd} / n-\mathrm{InP}$, поскольку ранее показано [2], что анодный оксид, созданный на $n$-InP, ведет себя как омическое сопротивление во всем исследованном интервале температур. При этом основное внимание обращено на изучение влияния концентрации водорода в газовой смеси на кинетику фототока короткого замыкания диодов Шоттки $\mathrm{Pd} / n$ - InP, так как изменение величины фототока диодов при их контакте с водородом оказалось более существенным по сравнению с изменением величины фотоэдс.

\section{2. Эксперимент}

Исследуемые структуры изготовлены на подложках $n-\operatorname{InP}(100)$ с концентрацией электронов $10^{16} \mathrm{~cm}^{-3}$. Площадь активной области чувствительного элемента составляла $1 \mathrm{mм}^{2}$. На поверхности подложки методом термического напыления в вакууме формировался слой $\mathrm{Pd}$ толщиной 25-40нм и контактный слой $\mathrm{Au}$ в форме креста для обеспечения равномерного растекания тока по поверхности структуры. Активная область была ограничена по периметру слоем нитрида кремния для снижения токов утечки. На обратной стороне подложки формировался сплошной омический контакт $\mathrm{Cr} / \mathrm{AuGe} / \mathrm{Au}$. Чипы с диодами размером $1.4 \times 1.7 \mathrm{Mm}$ монтировались на стандартных кристаллодержателях TO-18. Электрические и фотоэлектрические свойства диодов исследовались в воздушной среде без водорода и в газовой смеси, содержащей водород. При этом использовались стандартные азотно-водородные смеси газов с содержанием водорода 1.0, 3.95, 10 и 100 об \%.

Вольт-амперные характеристики (BAX) диодов $\mathrm{Pd} / n$-InP измерены в интервале температур 90-340 K, a фотоэлектрические - при $300 \mathrm{~K}$. При измерении фотоэлектрических характеристик в качестве источника освещения использовался светодиод с длиной волны излучения в максимуме 0.9 мкм.

При измерениях использовались следующие приборы: KEITLEY-2600A (Keithley Instruments, Inc.), синхронный детектор Stanford Research System SR-870, монохроматор МДР-2. Температурные зависимости ВАХ измерялись при плавном изменении температуры. Поскольку полная BAX (прямая и обратная ветви) записывалась за $3 \mathrm{c}$, а температура образца в течение этого времени изменялась только на $0.3 \mathrm{~K}$, то вносимые погрешности были в пределах погрешности измерения тока. Скорость записи данных при измерении фототока составляла 17 значений в секунду.

\section{3. Результаты и их анализ}

Анализ BAX диодов Шоттки $\mathrm{Pd} / n$-InP показал, что увеличение температуры уменьшает коэффициент выпрямления и величину напряжения отсечки диодов. Присутствие водорода в газовой смеси также уменьшает эти параметры. Данные изменения электрических харак- 
теристик различные авторы используют для регистрации наличия водорода в окружающей среде [6-9]. Однако в работах [1-5] показано, что для этого предпочтительнее использовать фотоэлектрические характеристики.

На рис. 1 представлены зависимости фототока короткого замыкания $I$ от времени $t$ для типичного диода $\mathrm{Pd} / n-\mathrm{InP}$ при его освещении (ток через светодиод $30 \mathrm{MA}$ ) и подаче газовой смеси с различным содержанием водорода.

Видно, что с увеличением концентрации водорода в газовой смеси увеличивается скорость спада фототока

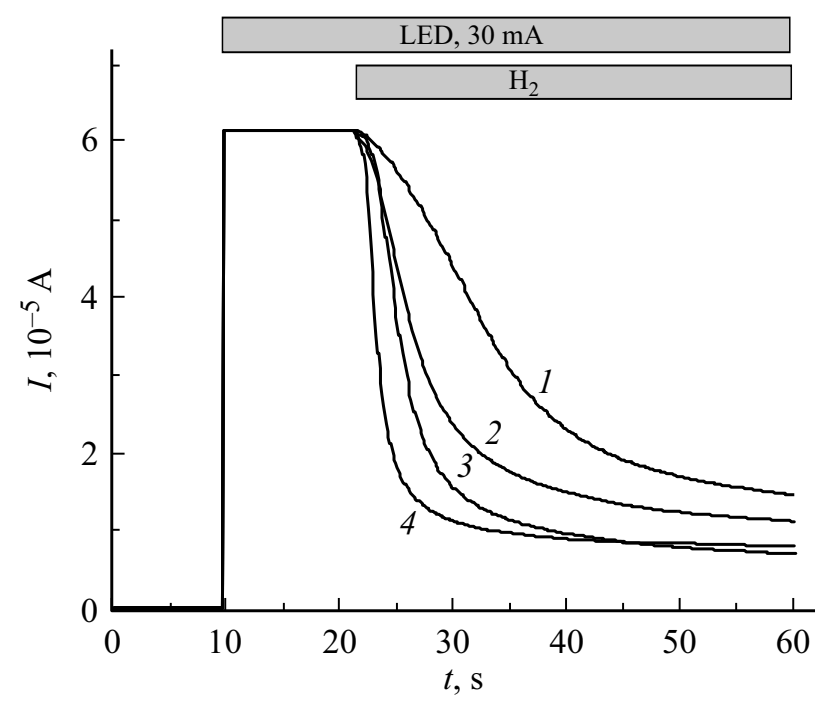

Рис. 1. Фототок короткого замыкания для типичного диода $\mathrm{Pd} / n$-InP при его освещении (ток через светодиод $30 \mathrm{MA}$ ) и подаче газовой смеси с различной концентрацией водорода (в об\%): $1-1,2-3.95,3-10,4-100)$.

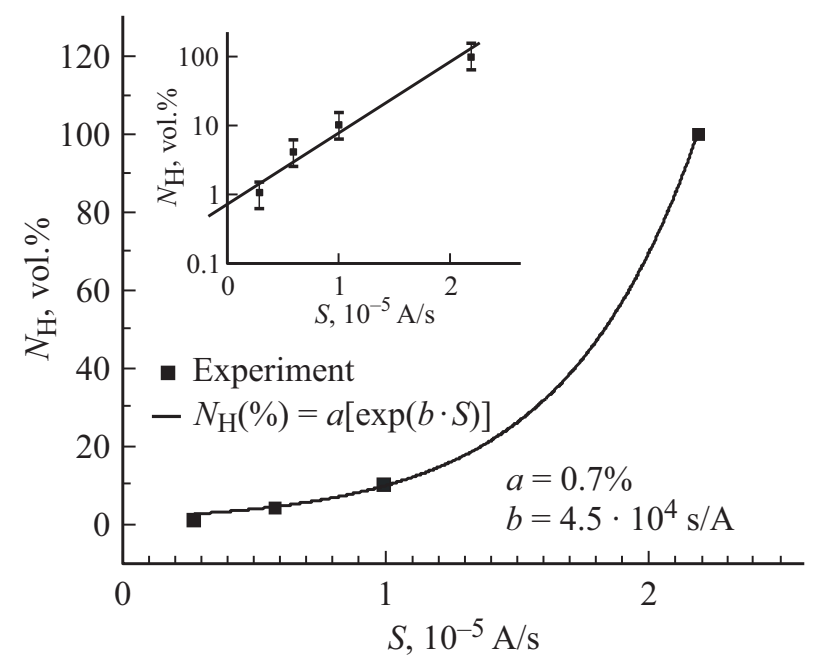

Рис. 2. Аппроксимация зависимости „концентрация водородаскорость изменения фототока“ при токе через светодиод 30 мА. На вставке эта зависимость представлена в полулогарифмических координатах, ее линейность подтверждает экспоненциальность установленного закона.

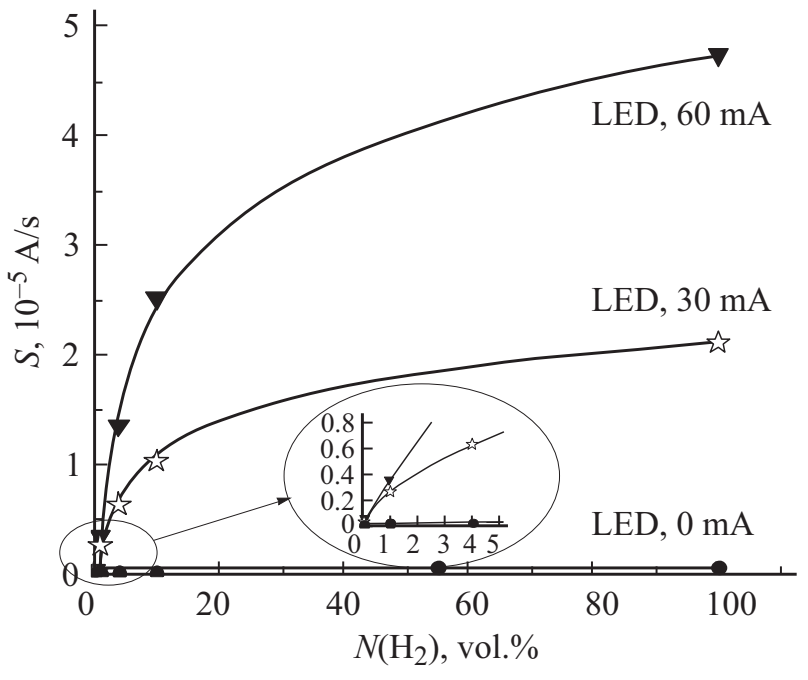

Рис. 3. Зависимость скорости изменения фототока короткого замыкания от концентрации водорода в газовой смеси для типичного диода Шоттки $\mathrm{Pd} / n$-InP при токах через светодиод, освещающий структуру: 0, 30 и 60 мА.

короткого замыкания. Этот экспериментальный факт может быть использован для количественного определения концентрации водорода в окружающей среде.

В данном случае закон, связывающий концентрацию водорода в газовой смеси и скорость изменения фототока короткого замыкания через ДШ $\mathrm{Pd} / n-\mathrm{InP}$, имеет экспоненциальный вид (рис. 2) $N_{\mathrm{H}}=a \cdot \exp (b S)$, где $N_{\mathrm{H}}$ - концентрация водорода в газовой смеси в об\%; $S$ - скорость изменения фототока короткого замыкания через ДШ $\mathrm{Pd} / n$-InP на начальном участке зависимости „фототок-время“, начиная с момента контакта ДШ с газовой смесью; $a$ и $b-$ постоянные, зависящие от толщины слоя палладия и освещенности ДШ.

С увеличением тока через светодиод, освещающий структуру, т.е. с увеличением интенсивности освещения, увеличиваются как скорость изменения фототока короткого замыкания при контакте диода с водородом, так и скорость реакции диода на присутствие водорода в газовой смеси (рис. 3). Это значит, что в перспективе чувствительностью и быстродействием фотоэлектрического датчика водорода можно управлять с помощью изменения освещенности его активного элемента, изготовленного на основе диода $\mathrm{Pd} / n$-InP.

\section{4. Заключение}

Представленные результаты показывают, что на основе диодов Шоттки $\mathrm{Pd} / n$-InP так же, как и на основе МДП-структур Pd/оксид/n-InP [5], могут быть созданы быстродействующие сенсоры водорода, позволяющие количественно определять концентрацию водорода в окружающей газовой среде, способные работать при комнатных температурах. 


\section{Список литературы}

[1] Е.А. Гребенщикова, В.В. Евстропов, Н.Д. Ильинская, Ю.С. Мельников, О.Ю. Серебренникова, В.Г. Сидоров, В.В. Шерстнев, Ю.П. Яковлев. ФТП, 49 (3), 376 (2015).

[2] А.Н. Именков, Е.А. Гребенщикова, В.А. Шутаев, А.М. Оспенников, В.В. Шерстнев, Ю.П. Яковлев. ФТП, 50 (7), 946 (2016).

[3] Е.А. Гребенщикова, А.Н. Именков, В.А. Шутаев, Н.Д. Ильинская, А.М. Оспенников, Ю.П.Яковлев. Патент на полезную модель № 166907 (2016).

[4] Е.А. Гребенщикова, А.А. Капралов, В.Г. Сидоров, В.А. Шутаев, Ю.П. Яковлев. Патент на полезную модель № 181295 (2018).

[5] Е.А. Гребенщикова, Х.М. Салихов, В.Г. Сидоров, В.А. Шутаев, Ю.П.Яковлев. ФТП, 52 (10), 1183 (2018).

[6] B. Podlepetsky, M. Nikiforova, A. Kovalenko. Sensors Actuators B, 254, 1200 (2018).

[7] Yen-I Chou, Chia-Ming Chen, Wen-Chau Liu, Huey-Ing Chen. IEEE Electron Dev. Lett., 26 (2), 62 (2005).

[8] K. Skucha, Zh. Fan, K. Jeon, A. Javey, B. Boser. Sensors Actuators B, 145, 232 (2010).

[9] J. Grym, O. Procházková, R. Yatskiv, K. Piksová. Nanoscale Res. Lett., 6, 392 (2011).

Редактор Г.А. Оганесян

\section{Hydrogen concentration infiuence on the photocurrent of $\mathbf{P d} / \boldsymbol{n}-\mathbf{I n P}$ Shottky diodes}

E.A. Grebenshchikova ${ }^{1}$, V.G. Sidorov ${ }^{2}$, V.A. Shutaev ${ }^{1}$, Yu.P. Yakovlev ${ }^{1}$

${ }^{1}$ loffe Institute, 194021 St. Petersburg, Russia

2 IBSG Co., Ltd,

194021 St. Petersburg, Russia

Abstract The rate of change of the short-circuit photocurrent of $\mathrm{Pd} / n$-InP Schottky diodes (SD) is studied depending on the presence of hydrogen in the gas mixture with the concentration of $\mathrm{H}_{2}$ in the range of $1-100 \mathrm{vol} \%$. It is shown that when the gas mixture containing hydrogen and the illumination $(\lambda=0.9 \mu \mathrm{m})$ are simultaneously influence the SD, the hydrogen concentration in the gas mixture and the rate of change of the photocurrent of the $\mathrm{Pd} / n$-InP diode are related exponentially. As the illumination intensity increases, the rate of the SD reaction increases for the presence of hydrogen in the gas mixture. 